\title{
RESOURCE CONTROL BY INTRODUCING AN ENVIRONMENTAL CURRENCY: COMPARISON OF FEEDSTOCK SOURCES FOR POLYETHYLENE PRODUCTION
}

\author{
Guido Grause * \\ Graduate School of Environmental Studies, Tohoku University, Aramaki Aza Aoba 6-6-20 Aoba-ku, Sendai 980-8579, Japan
}

Article Info:
Received:
12 June 2018
Revised:
10 October 2018
Accepted:
12 December 2018
Available online:
8 March 2019
Keywords:
Resource shares
Trade-off
Decarbonization
Ecopoints
Polyethylene
Fossil fuel
Biomass

Article Info:

Received:

12 June 2018

10 October 2018

Available online:

8 March 2019

Resource share

Trade-of

Decarbonization

Polyethylene

Biomass

\begin{abstract}
The uncontrolled resource consumption of our time causes serious ecological and economic problems. The continuation of high consumption of fossil fuels triggers climate change, while important metal ore deposits may be depleted within the near future. This situation requires a new kind of solution. For this purpose, the Ecopoint concept is proposed for the limitation of the consumption of fossil fuels and abiotic other non-renewable resources, as well as the land used to produce renewable ones. In this concept, the world's population is provided with resource shares (Ecopoints) that are used for purchasing products containing virgin resources. Using the polymerization of high density polyethylene as an example, it is shown that the Ecopoints concept favours options like sugar-based biomass (sweet sorghum, sugarcane, sugar beet) as a feedstock for bioethanol derived ethylene and waste materials (waste plastic, municipal solid waste) as a feedstocks for ethylene derived from cracking or gasification/Fischer-Tropsch synthesis over the conventional use of fossil fuel derived ethylene.
\end{abstract}

\section{INTRODUCTION}

When I was asked a few years ago to prepare a lesson regarding an environmental topic, I spontaneously decided to introduce my perception of the future of plastics. However, what role could plastics have in a world striving for decarbonization? Carbon is the main component in most plastics, and most of that carbon comes from fossil fuels (Thompson et al., 2009). One could argue that the replacement of fossil fuels by biomass is the most proper solution (Iwata, 2015; van den Oever and Molenveld, 2017). However, Cao et al. (2015) calculated that an area of 350 $\mathrm{km}^{2}$ would be necessary for the production of 100 ktons of polyethylene (PE) from the fermentation of sugarcane. Taking this value as an average for future plastic production, shifting the current annual production of more than 300 Mtons of plastic ("Plastics - the Facts 2017", 2018) from fossil fuel to biomass would require an area of more than $1,000,000 \mathrm{~km}^{2}$ - about $2 \%$ of the worldwide agricultural area (FAOSTAT, 2015). From these numbers it is quite clear that more is required than shifting production from one resource to another. If the reduction in $\mathrm{CO}_{2}$ emissions from fossil fuel consumption is paid for by a decreasing area for natural habitats, $\mathrm{CO}_{2}$ emissions from land use change and biodiversity loss might be a bad trade-off (Liu et al., 2015).
Trade-offs are common effect of replacing one resource with another without a clear concept how this shift might affect the overall sustainability (Acheampong et al., 2017; Gibon et al., 2017). Therefore, a system for resource control management was recently suggested called "Ecopoint" (Grause, 2018). In this system, the population is provided with a proportion of a finite number of resource shares. Consumers use Ecopoints for purchasing virgin resources incorporated in products. Merchants pass them through manufacturers to resource producers, who return them to the emitting authority as a mining fee. Since the total number of Ecopoints is finite, the amount of mined resources is limited. Each resource has an allocated price. A list of resources and the calculation method was provided by Grause (2018). By increasing the prices required for resource extraction over the years, a sustainable level of resource consumption may be achieved.

In this work, the effect of the Ecopoint system on the production of high-density polyethylene (HDPE) is examined. The conventional method of HDPE production makes use of fossil fuel derived ethylene as a feedstock. Nowadays alternative production routes for ethylene from other sources have been proposed (Belboom and Léonard, 2014; Tsiropoulos et al., 2015). Ethylene can be produced from biomass by the dehydration of fermentation derived eth- 
anol. Commercial HDPE with sugarcane as a feedstock is produced in Brazil. Ethylene is also accessible by the gasification of carbon-containing materials with the subsequent conversion of the synthesis gas by Fischer-Tropsch synthesis or other comparable processes (Feng et al., 2018; Schneider et al., 2018).

All these alternative processes lack cost-effectiveness, since fossil fuels are too cheap compared with the damage they do, while other types of feedstocks are not competitive (Covert et al., 2016). The Ecopoint concept does not improve competitiveness by raising fossil fuel prices as carbon taxes would do, but by limiting the overall resource consumption. Resources with a low Ecopoint price are favoured, since more of them can be consumed.

In the present work, the Ecopoint values of 13 different feedstocks - including fossil fuel, biomass, and waste and three different ethylene production routes - naphtha cracking, fermentation, and gasification - are compared for the production of HDPE.

\section{METHODS}

\subsection{Goal and Scope}

The aim of this work is the comparison of the resource consumption of different HDPE production routes. For this purpose, the resource consumption of these routes using different types of feedstocks were calculated using openLCA (v1.5) and global undefined system models derived from the commercial Ecoinvent database (v3.2) (Ecoinvent). The Ecopoint price was then calculated from the corresponding resource consumption using the data from Table 1 in Grause (2018). The use of global undefined system models was necessary, since the aim of this research was not the evaluation of environmental impacts, where avoided production is taken into account, but the summation of resource consumption that would lead to a certain Ecopoint price. Waste materials are by definition free of charge. Therefore, all upstream steps contributing to the resource consumption were included in the analysis. Cutoff conditions can be found in (Grause, 2018). Economic allocation was chosen as the price level of by-products has to be considered. The most important processes involved in the production of HDPE from various feedstocks are shown in the supplementary material.

Heat and power generation can be used as an example for this approach. If electricity is required for the process, the superfluous heat from the production process is commonly used in LCA to reduce the environmental impact by replacing heat from other sources, which causes a reduction in the environmental impact. In the present approach however, both electricity and heat are charged independently with Ecopoints for their resource consumption. Furthermore, heat and electricity show strong differences in their prices, which are accounted for by the economic allocation. Giving heat the same price as electricity would make it artificially expensive to the point of being economically infeasible. Therefore, energy producers should divide resource costs based on the market situation at the time of calculation.

\subsection{Process selection}

For the comparison of HDPE production, three different routes for ethylene production with 13 different feedstocks were selected. Ethylene from fossil fuel is obtained from steam cracking of naphtha. The same route (naptha replacement) was used for the utilization of waste plastic. The second production route is the fermentation of biomass and dehydration of the resulting ethanol for the formation of ethylene. The third route is the conversion of wood and municipal solid waste (MSW) into synthesis gas through gasification, followed by Fischer-Tropsch synthesis to obtain ethylene. Details of this process are given by Nuss et al. (2013). One model included up to 700 single processes (Figure 1).

Some of the processes required for this analysis were not available in the Ecoinvent database. For all scenarios the same process for high-density polyethylene polymerization was used (CPMDatabase). Data for the steam cracking of naphtha required for the production of ethylene from fossil fuel and waste plastics, the dehydration of bioethanol required for the production of ethylene from biomass via fermentation, and the production of synthesis gas from wood were obtained from the same database. The gasification of MSW was modelled by data provided by Nuss et al. (2013).

\section{RESULTS}

\subsection{Ecopoint price based on the production route}

Ecopoint (EP) prices differ greatly depending on the feedstock (Figure 2). Fossil fuel derived HDPE could expect a price of $10.1 \mathrm{EP}$; more than $99.6 \%$ of the price is related to the use of fossil fuels. Most of them (92\%) are required for the production of ethylene.

Ecopoint consumption can be strongly reduced by employing biomass as a feedstock. Low Ecopoint prices are achieved with ethylene derived from the fermentation of sweet sorghum (3.2 EP), sugarcane and whey (3.7 EP), and sugar beets (4.3 EP); all of these bio-feedstocks are sugar producers, allowing fermentation with a low energy consumption. Moreover, these feedstocks have a high land use efficiency. For the production of $1 \mathrm{~kg}$ of HDPE, sweet sorghum requires $0.5 \mathrm{~m}^{2} \mathrm{yr}^{-1}$, while sugar beet and sugar cane require $1.5 \mathrm{~m}^{2} \mathrm{yr}^{-1}$ (Figure 3). Whey is a by-product of cheese production with a high lactose content. Because of the low price of whey compared with cheese, allocation provides a considerably low Ecopoint price. However, availability depends strongly on milk production and cow farming.

High-density polyethylene production from grass requires $5.4 \mathrm{EP}$. For $1 \mathrm{~kg}$ of HDPE, an area of $2.4 \mathrm{~m}^{2} \mathrm{yr}^{-1}$ is required (Figure 3). The lower Ecopoint price of $0.0607 \mathrm{EP} \mathrm{m}^{-2}$ $\mathrm{yr}^{-1}$ for pastures and meadows compared with $0.3509 \mathrm{EP}$ $\mathrm{m}^{-2} \mathrm{yr}^{-1}$ results in a price for land use comparable with that for sweet sorghum. However, lignocellulosic feedstocks requires a more sophisticated fermentation process. Another lignocellulosic feedstock is wood. The production requires $2.2^{\star} 10^{-3} \mathrm{~m}^{3}$ of wood $\left(1070 \mathrm{EP} \mathrm{m}^{-3}\right.$ ) (Figure 3 ) and results in an Ecopoint price of $6.3 \mathrm{EP}$ per $\mathrm{kg}$ of HDPE (Figure 2). The same result was achieved when ethylene was produced from wood by gasification and Fischer-Tropsch synthesis. 


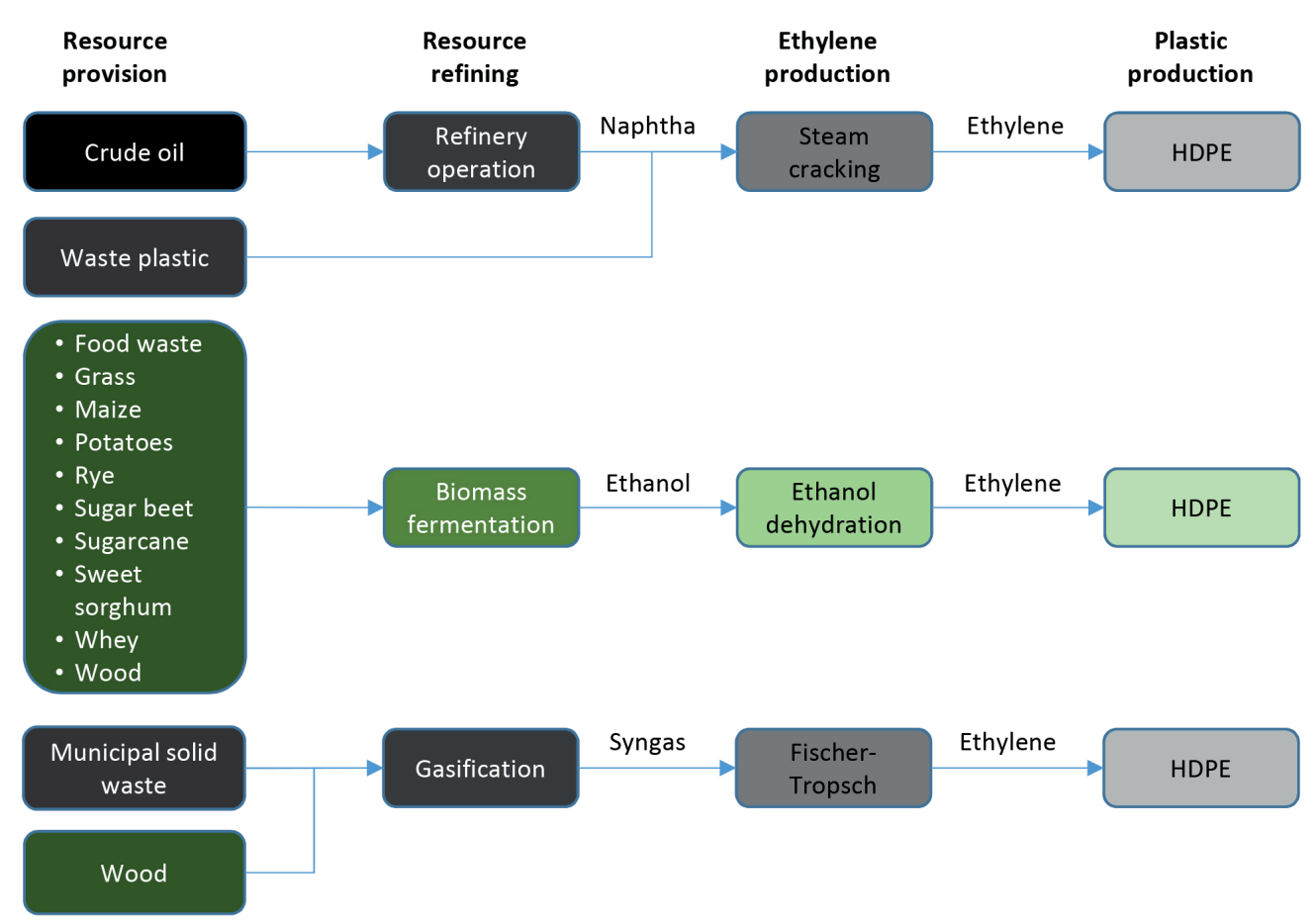

FIGURE 1: Production routes.

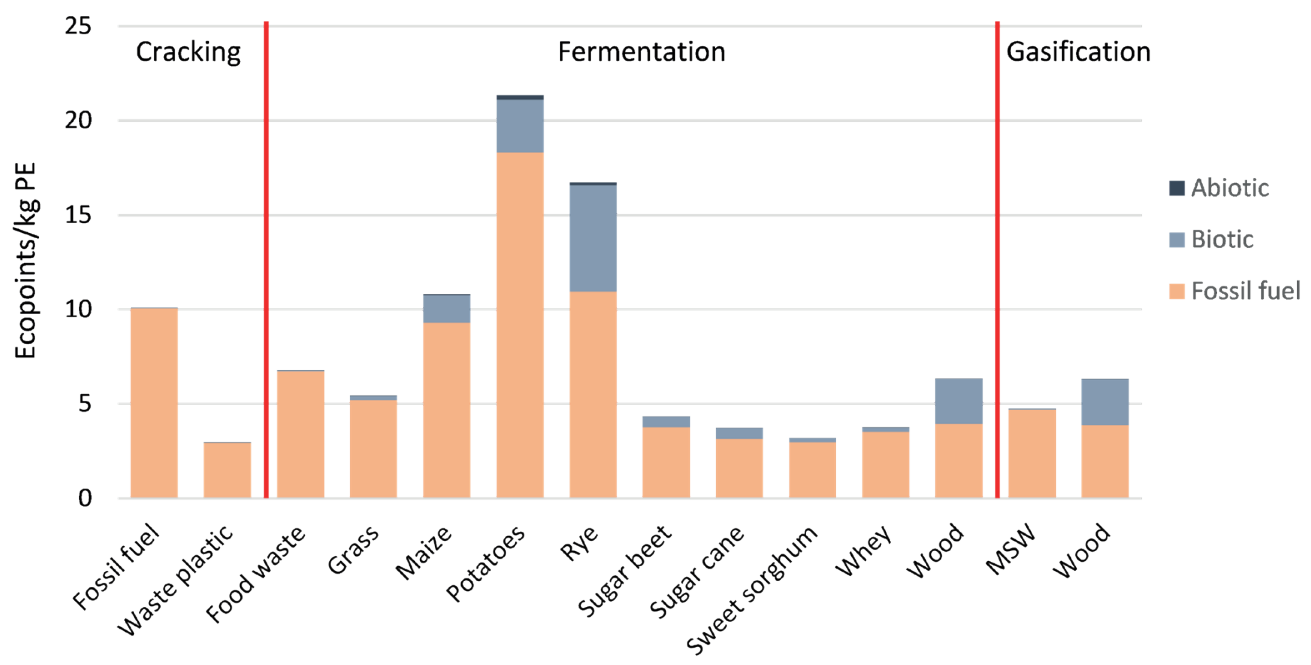

FIGURE 2: Ecopoint price for HDPE.

The prices for both grass and wood can decrease significantly, if waste materials are used, which have no cost in this system. Such materials might be garden waste, production off-cuts, wood pallets, etc. (Röder and Thornley, 2018).

Starch based biomass is not competitive in this system. Maize $\left(3.8 \mathrm{~m}^{2} \mathrm{yr}^{-1}\right)$, rye $\left(15.6 \mathrm{~m}^{2} \mathrm{yr}^{-1}\right)$, and potatoes $(7.2$ $\mathrm{m}^{2} \mathrm{yr}^{-1}$ ) require large areas for biomass production (Figure 3). This contributes to the high Ecopoint price of 10.8 EP for maize, 16.7 EP for rye, and 21.4 EP for potato derived HDPE (Figure 2).

Waste materials are very attractive for utilization, since resource fees are not required in this system. Waste plastic replacement of naphtha in the naphtha cracker for ethylene production generates a price of 3.0 EP. The MTCI gasification process (Nuss et al., 2013) utilizing MSW achieves a price of 4.7 EP. Additionally, replacing maize with food waste in the fermentation process results in $6.8 \mathrm{EP}$ (Figure 2). The replacement of freshly exploited resources by waste reduces Ecopoint prices significantly. Avoiding petrochemical naphtha and related efforts for its production reduces the HDPE price by $7.1 \mathrm{EP}$.

\subsection{Energy consumption}

There are three important types of energy employed in the present processes. Electricity and heat are used for industrial processes. The direct combustion of fossil fuels is especially required for metallurgical processes, while 


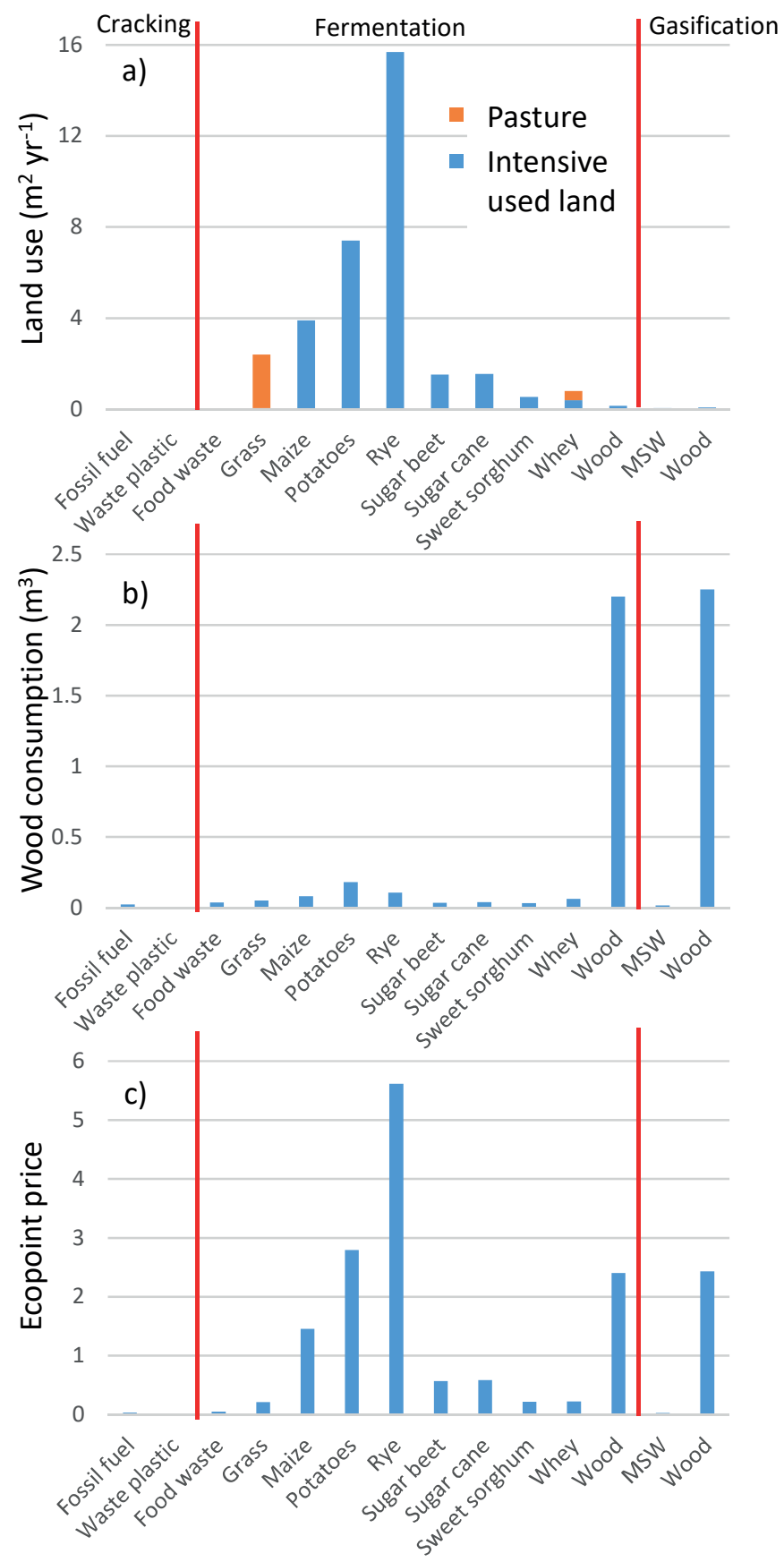

FIGURE 3: Biotic resources for $1 \mathrm{~kg}$ of HDPE: a) land use, b) wood consumption, c) Ecopoint price for biotic resources.

diesel is the most important energy source for agricultural machinery.

Electricity provides most of the energy required by the processes investigated in this work. Worldwide, the most important energy carrier is coal, followed by gas and hydropower (Figure 4). The share of fossil fuels in the production of high voltage electricity is $68 \%$. The share of electricity in the Ecopoint price strongly differs between HDPE production routes (Table 1). HDPE production from MSW and waste plastic-derived ethylene requires for the electricity supply $80 \%$ and $89 \%$ of the Ecopoint share, respectively. This is not a sign of an extraordinary energy consumption, but is instead related to the absence of another major re- source input. The highest consumption is caused by the naphtha cracking process. All production routes including this process (fossil fuel, MSW, waste plastic, wood gasification) require for their electricity consumption between 2.6 and 3.8 EP. Other favourable feedstocks for HDPE production spend about $50 \%$ of the Ecopoint cost on electricity, and the main consumer is the polymerization process itself, followed by the dehydration of ethanol. Starch based feedstocks (maize, potato, rye) require a larger agricultural area and additional electricity for the intensive fermentation process, making these feedstocks inappropriate for HDPE production. The general reduction of the electricity component of the Ecopoint price might be achieved with 
the lowest effort. Replacing electricity production from coal, gas, and oil by renewable energy sources could decrease the Ecopoint burden significantly (Grause, 2018).

Heat is required for the fermentation and ethanol dehydration processes. The dehydration process requires roughly $1 \mathrm{EP}$ for the heat provision. The additional heat consumption required for the production of feedstock is below $4 \%$ of the total Ecopoint cost for sugar based feedstocks and rises substantially for starch based feedstocks to around $20 \%$. One exception is the sugar beet, which requires a share of $11 \%$ from the total Ecopoint cost.

The use of agricultural diesel is negligible compared with other energy inputs for the production of HDPE. Diesel consumption reaches only a significant amount for the production of potatoes, where $17 \%$ of the total Ecopoint cost is spend for diesel.

The resource responsible for the highest Ecopoint share is coal. For most production routes, the share of coal ranges between 59 and $78 \%$, which correlates with the electricity and heat consumption (Table 1). The highest coal share $(78 \%)$ is required for grass as feedstock. In addition to the coal required for electricity and industrial heat production, coal is also used as a fuel in small heating appliances for the ethanol production from grass. Starch based feedstocks require additional heat for fermentation, which is mainly provided by the gas heating that is responsible for the high gas consumption for these feedstocks. The gas consumption reflects the heating requirement for the fermentation process with values between 0.32 and 0.58 EP for sugar-based feedstocks and between 2.77 and 4.44 EP for starch based feedstocks. Gas consumption for HDPE production from fossil fuel, MSW, or waste plastic is mainly related to electricity production. Oil is used as diesel for transportation and agricultural activities and as heavy fuel oil for heat production. Conventional HDPE production

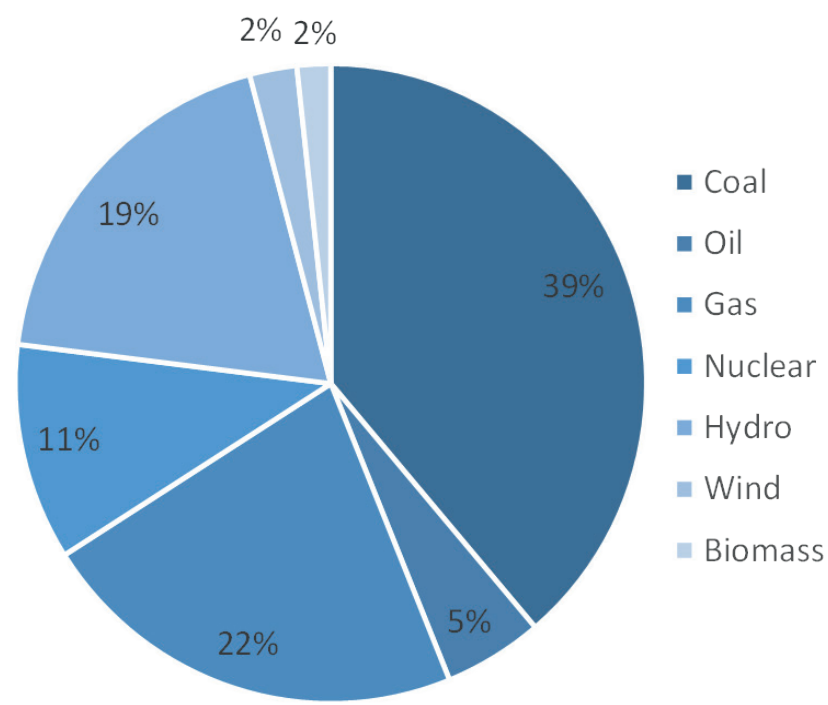

FIGURE 4: Global electricity mix.

also uses oil as feedstock for the production of ethylene. It should be noted that the oil consumption for HDPE production using potatoes as feedstock exceeds that of HDPE made from fossil fuels.

\subsection{Abiotic resources}

Abiotic resources represent only a small share of Ecopoints in this analysis. Polyethylene is a product consisting of carbon and hydrogen. Abiotic resource have only a supporting part in the production. Metals are used for agricultural machinery ( $\mathrm{Fe}, \mathrm{Cr}, \mathrm{Ni}, \mathrm{Al})$, construction of buildings ( $\mathrm{Al}, \mathrm{Cu}, \mathrm{Zn}, \mathrm{Fe})$, and the distribution of electricity (Al). In the production of HDPE from fossil fuel, iron is mainly used for the construction of pipelines and other oil field

TABLE 1: Some selected categories and their Ecopoint prices: Energy, fossil fuels, and abiotic resources. (HVE: high voltage electricity, Diesel: diesel used in agriculture, Al: aluminium, $\mathrm{BaSO}_{4}$ : barite, $\mathrm{Cr}$ : chromium, $\mathrm{Cu}$ : copper, Fe: iron, Ni: nickel, P: phosphorus, KCl: sylvite, Zn: Zinc).

\begin{tabular}{|c|c|c|c|c|c|c|c|c|c|c|c|c|c|c|c|c|c|}
\hline & HVE & Heat & Diesel & Coal & Gas & Oil & Al & $\mathrm{BaSO}_{4}$ & $\mathrm{Cr}$ & $\mathrm{Cu}$ & $\mathrm{Fe}$ & $\mathrm{Ni}$ & $\mathbf{P}$ & $\mathrm{KCl}$ & $\mathrm{Zn}$ & \multirow{2}{*}{$\begin{array}{c}\text { Biotic } \\
\text { EP } \\
\end{array}$} & \multirow{2}{*}{$\begin{array}{r}\text { Tota } \\
\text { EP }\end{array}$} \\
\hline & \multicolumn{3}{|c|}{ EP } & \multicolumn{3}{|c|}{ EP } & \multicolumn{9}{|c|}{$10^{-3}$ EP } & & \\
\hline Fossil fuel & 2.87 & 0.61 & & 2.86 & 0.76 & 6.44 & & 3.41 & & & 1.65 & & & & & 0.03 & 10.1 \\
\hline Food waste & 2.65 & 3.99 & & 3.14 & 2.31 & 1.27 & 1.67 & & & & 1.58 & & & & & 0.04 & 6.8 \\
\hline Grass & 2.50 & 2.62 & 0.15 & 4.20 & 0.42 & 0.58 & & & & & 2.16 & & & & & 0.21 & 5.4 \\
\hline Maize & 3.56 & 4.17 & 0.37 & 4.17 & 2.77 & 2.36 & 2.94 & 1.08 & 2.53 & & 9.47 & 26.8 & 15.5 & 14.0 & & 1.46 & 10.8 \\
\hline Potatoes & 6.15 & 5.81 & 3.69 & 7.28 & 4.44 & 6.60 & 10.6 & 3.24 & 7.15 & 15.1 & 28.9 & 76.5 & 53.0 & 38.3 & & 2.80 & 21.4 \\
\hline Rye & 3.88 & 4.38 & 0.94 & 4.68 & 3.03 & 3.25 & 5.62 & 1.53 & 4.34 & 9.99 & 12.5 & 44.1 & 47.4 & 34.0 & & 5.62 & 16.7 \\
\hline Sugar beet & 1.84 & 1.54 & 0.19 & 2.55 & 0.58 & 0.63 & & & & & 1.37 & & 2.51 & 2.12 & & 0.57 & 4.3 \\
\hline Sugar cane & 1.76 & 1.16 & 0.04 & 2.40 & 0.35 & 0.38 & & & & & 2.48 & & & 5.89 & & 0.58 & 3.7 \\
\hline Sweet sorghum & 1.65 & 1.16 & 0.06 & 2.28 & 0.32 & 0.37 & & & & & 1.34 & & 1.14 & 1.40 & & 0.22 & 3.2 \\
\hline Whey & 1.86 & 1.31 & 0.04 & 2.54 & 0.43 & 0.55 & & & & & 1.17 & & & 1.82 & & 0.22 & 3.7 \\
\hline Wood (fermentation) & 1.83 & 1.24 & 0.02 & 2.49 & 0.52 & 0.92 & 1.49 & & & & 1.77 & & & & 5.22 & 2.40 & 6.3 \\
\hline MSW & 3.78 & 0.20 & & 3.14 & 0.55 & 1.01 & 1.82 & & & & 1.61 & & & & & 0.03 & 4.7 \\
\hline Waste plastic & 2.63 & 0.04 & & 2.14 & 0.33 & 0.48 & & & & & & & & & & 0.008 & 3.0 \\
\hline Wood (gasification) & 3.16 & 0.17 & 0.00 & 2.67 & 0.50 & 0.71 & 9.84 & & & & 1.30 & & & & & 2.43 & 6.3 \\
\hline
\end{tabular}


constructions. Barite is used as drilling agent in the oil and gas industry. Therefore, its usage is strongly related to the consumption of these fossil fuels. Phosphate and sylvite are used for the production of fertilizers that are especially required for starch based feedstocks. The distribution of abiotic resources is shown in Table 1.

\section{DISCUSSION}

The Ecopoint system is an efficient way to express differences in resource utilization using a monetary value. Covert et al. (2016) called the low price for carbon dioxide a market failure of the current economic system. That is, fossil fuels are too cheap and their associated technologies are too advanced to give alternative approaches a fair chance to stand on the market. Without intervention the world's community will fail to keep the $2.0^{\circ} \mathrm{C}$ goal as agreed on in Paris.

In the present case of HDPE production, resource consumption puts an additional fee on the product. This could translate to additional US\$ 600 per ton for fossil fuel based HDPE at a price of US\$ 0.06 per Ecopoint (Grause, 2018). Waste and sugar-based feedstocks especially provide an alternative to conventional oil and gas-based HDPE. The replacement of fossil oil by waste plastic in refinery processes (Lopez et al., 2017) could reduce this fee to US\$ 180 (Figure 5). Starch-based feedstocks do not provide any advantage over fossil fuel. Maize-based HDPE is in the same Ecopoint price range as fossil fuel based HDPE, while plastic derived from rye or potatoes are even more expensive. Lignocellulosic feedstocks range between sugar-based and fossil fuel-based materials. Wood offers an advantage of US\$ 225 compared to fossil fuels. This is surprising, since it was reported earlier that such an advantage does not exist for the conversion of wood to energy (Grause, 2018).

Another important question is the availability of alternative resources. Sugar-based feedstocks require additional agricultural areas. For example, sweet sorghum can provide feedstock for 100 ktons HDPE on an area of $50 \mathrm{~km}^{2}$ $\mathrm{yr}^{-1}$, whereas sugarcane and sugar beets need $150 \mathrm{~km}^{2}$ $\mathrm{yr}^{-1}$ (Figure 3). This differs from Bos et al. (2012) and Cao et al. (2015), who found that both sugarcane and sugar beets require areas between 300 and $350 \mathrm{~km}^{2} \mathrm{yr}^{-1}$. The annual worldwide land use for the production of bioethanol is about 85 million $\mathrm{m}^{3}$ (Popp et al., 2014), which would be sufficient for the production of 45 Mtons of polyethylene. Additional conversion of sugar to ethanol is preferable. The current surplus capacity in sugar production and the end of the EU's sugar quota in 2017 puts small sugar producers into a precarious situation and forces them to adjust their product strategies. As an example, Fiji produces an excess of 1.4 Mtons of sugar that could be converted into 96,500 $\mathrm{m}^{3}$ ethanol (Chandra and Hemstock, 2016) or 51 ktons of polyethylene (Cao et al., 2015).

Liptow et al. (2015) and Budzinski and Nitzsche (2016) investigated the possible ethylene production from wood. Liptow et al. (2015) suggested tree tops and branches as possible feedstocks for ethylene production. They identified a potential of 4.9 Mtons $\mathrm{yr}^{-1}$ dry mass in Sweden. Budzinski and Nitzsche (2016) calculated the impacts of biorefineries, one of which could annually convert 400 ktons dry mass of beech wood into 41.6 ktons ethylene, 58.5 ktons organosolve lignin, 90.8 ktons hydrolysis lignin, and 38.4 ktons biomethane. They also found two regions in Germany capable of providing appropriate feedstocks. Herr et al. (2012) identified a potential for grass production of 266 Mtons $\mathrm{yr}^{-1}$ in Australia. Only $15 \%$ of that could provide more than $50 \%$ of the Australian petrol demand, if transformed into ethanol.

The availability of waste plastics depends strongly on the plastic consumption and collection systems. One part of the waste plastic stream can be recycled mechanically without any significant quality loss; another part can be depolymerized for monomer recovery (Grause et al., 2011). Only the remaining low quality waste should be subjected

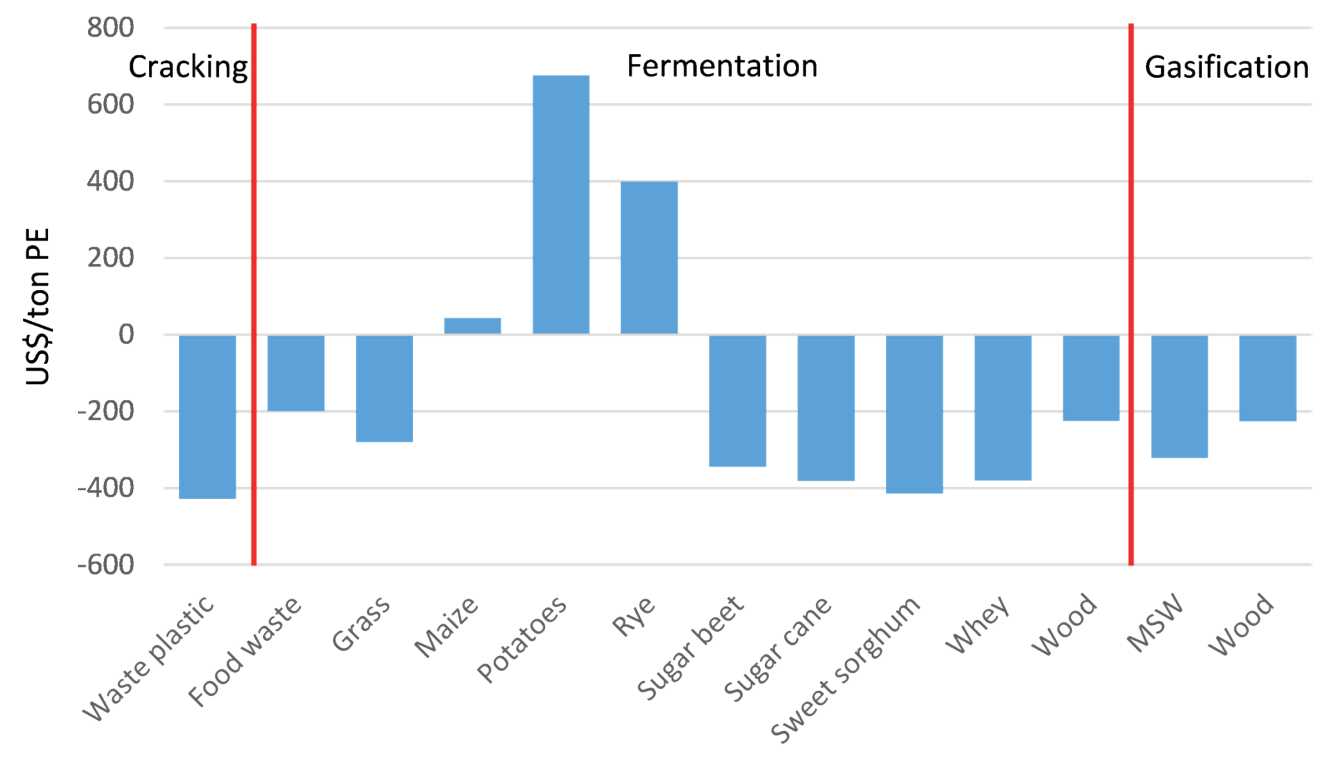

FIGURE 5: Additional price. 
to destructive measures such as thermal decomposition or gasification. This low density waste is often wide spread over a large catchment area and requires long distance transportation to the next treatment facility. Nevertheless, sufficient amounts of waste plastic are available (Zhang et al., 2016). The same is true for MSW (Kamaruddin et al., 2017). Composition and generation depend on urbanization level and economic development, but the organic content exceeds $50 \%$ in any case. Food waste dominates the MSW in countries with low GDP and paper and plastic in countries with high GDP.

All these examples show the general availability of carbon sources that can be used as chemical feedstocks. Availability of feedstocks depends strongly on local and regional circumstances. Many processes covered in this work produce ethanol as an intermediate product; all of them produce ethylene. However, one single process might not provide sufficient amounts of ethanol or ethylene for an industrial HDPE polymerization facility, and the production of HDPE does not require ethylene from a single source. As an example, it might be advantageous for an HDPE producer to obtain the main fraction of ethylene from the gasification of MSW generated by the close municipality and fill the gap to the production target with ethylene derived from the fermentation of lignocellulosic wood residues and grass.

In our current system, fossil fuels are extracted in some few key regions, transported around the world, and processed in huge industrial complexes, which are centralized in some major industrial areas. This will change with the end of the fossil fuel age. Production of chemical feedstocks will be decentralized depending on the availability of feedstocks: gasification of MSW and plastic in urbanized regions, wood fermentation and gasification in countries rich in forests, and fermentation of sugar containing crops in agricultural areas. Feedstocks might also be combined: there is no obvious reason that wood could not be fermented together with grass and garden garbage, or MSW could not be gasified together with wood and grass. Every region in the world is producing feedstocks appropriate for the conversion to ethanol and ethylene or any other substance that is required in the chemical industry.

The advantage of the fossil fuel producing industry is purely its size (Masih et al., 2010). Size provides synergy effects, which cannot be easily compensated for by new technologies. The Ecopoint concept limits resource consumption by limiting resource shares. Since the price for natural gas, crude oil, and coal are comparable high in this system, only a limited amount of fossil fuels can be provided. In order to improve energy supply, energy sources with a lower Ecopoint price have to be employed (Grause, 2018). The more hydropower, wind, solar, and geothermal energy is used, the smaller the share for fossil fuels becomes. Vandermeulen et al. (2012) describe possible pathways for the transition from a fossil fuel-based to a bio-based society. However, little is known about the change that will occur to fossil fuel distribution networks during this transition. One scenario could be that at first some small or old refineries and some remote or difficult to exploit coal mines and gas fields - which are not able to compete in a tighter market - could be shut down, increasing the trans- portation distance for crude fuels and refined products. With an increasing share of alternative feedstocks, it becomes increasingly difficult to maintain the infrastructure consisting of exploitation structures, transport vessels, pipelines, refineries, coke ovens, and the distribution networks for fossil fuel derived products. At the tipping point, it might take only a few years for fossil fuels to disappear from some applications.

Such a scenario might keep product prices on a constant level. A high Ecopoint price triggers developments that promote resource conservation. Renewable energy, recycling, and share economy reduce the Ecopoint price accordingly. In the end, a sustainable level of resource consumption might be achieved without endangering the quality of life.

\section{CONCLUSIONS}

The Ecopoint concept supports the transition towards a sustainable society. Feedstocks for HDPE productions were identified promoting this development. Waste materials, sugar and lignocellulosic based feedstocks require less resources than fossil fuels and starch based biomass. Ethylene derived from bioethanol or synthesis gas has to be provided by numerous sources, which leads to a decentralized feedstock supply. This requires new industrial and economic strategies and policy changes. It might open up a pathway to a sustainable way of life without significant changes in the life quality.

\section{ACKNOWLEDGEMENTS}

This research was supported by the Ministry of Education, Science, Sports, and Culture, Grand-in-Aid for Scientific Research (C), 15K05581, 2015.

Declarations of interest: none

\section{REFERENCES}

Acheampong, M., Ertem, F. C., Kappler, B., \& Neubauer, P. (2017). In pursuit of Sustainable Development Goal (SDG) number 7: Will biofuels be reliable? Renew. Sust. Energ. Rev., 75, 927-937. doi: https:// doi.org/10.1016/j.rser.2016.11.074

Belboom, S., \& Léonard, A. (2014). Importance of LUC and ILUC on the carbon footprint of bioproduct: case of bio-HDPE. Matériaux \& Techniques, 102(2), 201.

Bos, H. L., Meesters, K. P. H., Conijn, S. G., Corré, W. J., \& Patel, M. K. (2012). Accounting for the constrained availability of land: a comparison of bio-based ethanol, polyethylene, and PLA with regard to non-renewable energy use and land use. Biofuels Bioprod. Biorefining, 6(2), 146-158. doi: doi:10.1002/bbb.1320

Budzinski, M., \& Nitzsche, R. (2016). Comparative economic and environmental assessment of four beech wood based biorefinery concepts. Bioresource Technol., 216, 613-621. doi: https://doi. org/10.1016/j.biortech.2016.05.111

Cao, V., Margni, M., Favis, B. D., \& Deschênes, L. (2015). Aggregated indicator to assess land use impacts in life cycle assessment (LCA) based on the economic value of ecosystem services. J. Clean. Prod., 94, 56-66. doi: https://doi.org/10.1016/j.jclepro.2015.01.041

Chandra, V. V., \& Hemstock, S. L. (2016). The Potential of Sugarcane Bioenergy in Fiji. Sugar Tech, 18(3), 229-235. doi: 10.1007/s12355015-0409-7

Covert, T., Greenstone, M., \& Knittel, C. R. (2016). Will We Ever Stop Using Fossil Fuels? J. Econ. Perspect., 30(1), 117-138. doi: doi: 10.1257/jep.30.1.117

CPMDatabase. from http://cpmdatabase.cpm.chalmers.se/

Ecoinvent. from https://v32.ecoquery.ecoinvent.org/Home/Index 
FAOSTAT. (2015). Retrieved from: http://www.fao.org/faostat/ en/\#home

Feng, J., Xiulian, P., Ke, G., Yuxiang, C., Gen, L., \& Xinhe, B. (2018). ShapeSelective Zeolites Promote Ethylene Formation from Syngas via a Ketene Intermediate. Angew. Chem. Int. Ed., 57(17), 4692-4696. doi: doi:10.1002/anie.201801397

Gibon, T., Arvesen, A., \& Hertwich, E. G. (2017). Life cycle assessment demonstrates environmental co-benefits and trade-offs of low-carbon electricity supply options. Renew. Sust. Energ. Rev., 76, 12831290. doi: https://doi.org/10.1016/j.rser.2017.03.078

Grause, G. (2018). Resource control by a sustainability based currency equivalent. J. Clean. Prod., 200, 533-541. doi: 10.1016/j.jclepro.2018.07.297

Grause, G., Buekens, A., Sakata, Y., Okuwaki, A., \& Yoshioka, T. (2011). Feedstock recycling of waste polymeric material. J. Mater. Cycles Waste Manage., 13(4), 265-282. doi: 10.1007/s10163-011-0031-z

Herr, A., O'Connell, D., Farine, D., Dunlop, M., Crimp, S., \& Poole, M. (2012). Watching grass grow in Australia: is there sufficient production potential for a biofuel industry? Biofuels Bioprod. Biorefining, 6(3), 257-268. doi: doi:10.1002/bbb.1321

Iwata, T. (2015). Biodegradable and Bio-Based Polymers: Future Prospects of Eco-Friendly Plastics. Angew. Chem. Int. Ed., 54(11), 3210-3215. doi: doi:10.1002/anie.201410770

Kamaruddin, M. A., Yusoff, M. S., Rui, L. M., Isa, A. M., Zawawi, M. H., \& Alrozi, R. (2017). An overview of municipal solid waste management and landfill leachate treatment: Malaysia and Asian perspectives. Environ. Sci. Pollut. Res., 24(35), 26988-27020. doi: 10.1007/ s11356-017-0303-9

Liptow, C., Tillman, A.-M., \& Janssen, M. (2015). Life cycle assessment of biomass-based ethylene production in Sweden - is gasification or fermentation the environmentally preferable route? Int. J. Life. Cycle Assess., 20(5), 632-644. doi: 10.1007/s11367-0150855-1

Liu, J., Mooney, H., Hull, V., Davis, S. J., Gaskell, J., Hertel, T., . . Li, S. (2015). Systems integration for global sustainability. Science, 347(6225). doi: $10.1126 /$ science.1258832

Lopez, G., Artetxe, M., Amutio, M., Bilbao, J., \& Olazar, M. (2017). Thermochemical routes for the valorization of waste polyolefinic plastics to produce fuels and chemicals. A review. Renew. Sust. Energ. Rev., 73, 346-368. doi: https://doi.org/10.1016/j.rser.2017.01.142
Masih, M., Algahtani, I., \& De Mello, L. (2010). Price dynamics of crude oil and the regional ethylene markets. Energy Econ., 32(6), 14351444. doi: https://doi.org/10.1016/j.eneco.2010.03.009

Nuss, P., Gardner, K. H., \& Bringezu, S. (2013). Environmental Implications and Costs of Municipal Solid Waste-Derived Ethylene. J. Ind. Ecol., 17(6), 912-925. doi: 10.1111/jiec.12066

Plastics - the Facts 2017 (P. E. M. R. G. (PEMRG), Trans.). (2018) (pp. 23): Plastics Europe.

Popp, J., Lakner, Z., Harangi-Rákos, M., \& Fári, M. (2014). The effect of bioenergy expansion: Food, energy, and environment. Renew. Sust. Energ. Rev., 32, 559-578. doi: http://dx.doi.org/10.1016/j. rser.2014.01.056

Röder, M., \& Thornley, P. (2018). Waste wood as bioenergy feedstock. Climate change impacts and related emission uncertainties from waste wood based energy systems in the UK. Waste Manage., 74, 241-252. doi: https://doi.org/10.1016/j.wasman.2017.11.042

Schneider, J., Struve, M., Trommler, U., Schlüter, M., Seidel, L., Dietrich, S., \& Rönsch, S. (2018). Performance of supported and unsupported $\mathrm{Fe}$ and $\mathrm{Co}$ catalysts for the direct synthesis of light alkenes from synthesis gas. Fuel Process. Technol., 170, 64-78. doi: https://doi. org/10.1016/j.fuproc. 2017.10.018

Thompson, R. C., Swan, S. H., Moore, C. J., \& vom Saal, F. S. (2009). Our plastic age. Philos. Trans. R. Soc. B-Biol. Sci., 364(1526), 19731976. doi: $10.1098 /$ rstb. 2009.0054

Tsiropoulos, I., Faaij, A. P. C., Lundquist, L., Schenker, U., Briois, J. F., \& Patel, M. K. (2015). Life cycle impact assessment of bio-based plastics from sugarcane ethanol. J. Clean. Prod., 90, 114-127. doi: https://doi.org/10.1016/j.jclepro.2014.11.071

van den Oever, M., \& Molenveld, K. (2017). Replacing fossil based plastic performance products by bio-based plastic productsTechnical feasibility. New Biotech., 37, 48-59. doi: https://doi. org/10.1016/j.nbt.2016.07.007

Vandermeulen, V., Van der Steen, M., Stevens, C. V., \& Van Huylenbroeck, G. (2012). Industry expectations regarding the transition toward a biobased economy. Biofuels Bioprod. Biorefining, 6(4), 453464. doi: doi:10.1002/bbb. 1333

Zhang, X., Lei, H., Chen, S., \& Wu, J. (2016). Catalytic co-pyrolysis of lignocellulosic biomass with polymers: a critical review. Green Chem., 18(15), 4145-4169. doi: 10.1039/C6GC00911E 